\title{
CONDICIONAMENTO OSMÓTICO EM SEMENTES DE CEBOLA: I. EFEITOS SOBRE A GERMINAÇÃO
}

\author{
Maria Fernanda Otero Otumuro Trigo ${ }^{1,2 *}$; Jorge Luiz Nedel ${ }^{1,2}$; Luis Felipe Navia Trigo ${ }^{1,2}$ \\ ${ }^{1}$ Depto. de Fitotecnia - FAEM/UFPel, C.P. 354 - CEP: 96010-900 - Pelotas, RS. \\ ${ }^{2}$ Bolsista do CNPq. \\ *e-mail: mftrigo@rio.com.br
}

RESUMO: Lotes de sementes de cebola, cultivares Aurora e Petrolini, de diferentes níveis de vigor, foram osmocondicionados utilizando soluções aquosas de $\mathrm{KNO}_{3}$ e de PEG, nos tempos de embebição de 0 (controle), 24 e 48 horas, à temperatura de $20^{\circ} \mathrm{C}$ e com aeração constante. Após os tratamentos as sementes foram secas em estufa a $30^{\circ} \mathrm{C}$ até atingirem os níveis iniciais de umidade, em seguida foi efetuada uma divisão das sementes em porções iguais: uma foi armazenada em sacos de papel no interior de um dessecador por seis meses e a outra foi submetida imediatamente as avaliações em laboratório. Os resultados mostraram que a velocidade e a percentagem total de germinação sob condições de estresse aumentaram nas sementes de cebola osmocondicionadas. As sementes osmocondicionadas com soluções aeradas de $\mathrm{KNO}_{3}$ por 24 horas apresentaram melhor desempenho. O condicionamento osmótico pode reverter o processo de envelhecimento natural de sementes de cebola. Sementes de cebola osmocondicionadas mantiveram sua viabilidade por seis meses de armazenamento.

Palavras-chave: Allium cepa, priming, viabilidade, qualidade, armazenamento

\section{OSMOTIC CONDITIONING OF ONION SEEDS: I. GERMINATION EFFECTS}

ABSTRACT: Onion seed lots (varieties Aurora and Petrolini) of different vigor levels, were osmoconditioned using aerated aqueous solutions of $\mathrm{KNO}_{3}$ and $\mathrm{PEG}$ at $20^{\circ} \mathrm{C}$. In addition three soaking times $(0,24$ and 48 hours) were evaluated. Following each treatment, seeds were dried in an oven at $30^{\circ} \mathrm{C}$ until they reached initial moisture levels. Then seeds were divided into two portions. One batch was stored in a dessecador for six months, while the other was immediately evaluated. Results showed that the rate of germination and germination under stress conditions increased in osmoconditioned onion seeds. Treatment with $\mathrm{KNO}_{3}$ for 24 hours presented the best performance. Osmotic conditioning may reverse the process of natural aging of onion seeds. Osmoconditioned onion seeds maintained their physiologic quality up to six months of storage.

Key words: Allium cepa, priming, viability, quality, storage

\section{INTRODUÇÃO}

A produção de mudas é uma fase que requer atenção especial na cultura da cebola. Devido ao tamanho reduzido, as sementes desta espécie são muito sensíveis aos constantes ciclos de hidratação-desidratação no solo. A época de semeadura, que vai de abril a julho, freqüentemente coincide com solos frios no Rio Grande do Sul, além disso, conforme salientam Amaral et al. (1987), a produção de sementes de cebola enfrenta uma série de problemas, como a baixa produtividade por área e a baixa qualidade das sementes obtidas. Assim, é muito comum ocorrerem falhas no estande inicial ou atrasos na germinação, que podem comprometer as etapas posteriores no ciclo da cultura.
Várias técnicas têm sido propostas com a finalidade de melhorar a percentagem de germinação das sementes, reduzir o tempo necessário entre a semeadura e a emergência das plântulas, bem como aumentar a tolerância às condições ambientais adversas, como as baixas temperaturas e a deficiência de água no solo no momento da semeadura. Entre elas, o condicionamento osmótico das sementes (priming), isto é, a pré-embebição em uma solução osmótica que controla a hidratação das sementes, não permitindo que ocorra a protrusão da radícula (Heydecker \& Gibbins, 1978; Bradford, 1986 e McDonald, 1998), se destaca como uma das mais promissoras.

Incrementos na longevidade e na taxa de germinação das sementes associados ao 
osmocondicionamento também têm sido reportados. Em algumas espécies, como ervilha, tomate, cenoura (Savino et al., 1979 e Liu et al., 1996) e cebola (Dearman et al., 1986), o osmocondicionamento aumentou a capacidade de armazenamento. Burgass \& Powell (1984) sugerem que parte da melhora no comportamento germinativo observado em sementes osmocondicionadas advém da reparação de deterioração sofrida pela semente após a maturação. Segundo Powell (1998) as evidências sugerem que a ativação dos mecanismos de reparação metabólica é o que mais contribui para benefícios alcançados pelo osmocondicionamento. Knypl \& Khan (1981), salientam que o condicionamento osmótico das sementes pode ampliar a época de semeadura e aumentar a uniformidade do estabelecimento das plântulas no campo, refletindo-se em maior produtividade da cultura. Este fato se reveste de considerável importância quando se deseja obter uma emergência uniforme de plântulas. Desta forma, devido à relevância do problema e à carência de informações sobre o assunto, este estudo objetivou avaliar os efeitos imediatos e latentes do condicionamento osmótico sobre a germinação de sementes de cebola.

\section{MATERIAL E MÉTODOS}

O estudo foi conduzido no Laboratório de Análise de Sementes da Faculdade de Agronomia Eliseu Maciel, Universidade Federal de Pelotas, no ano de 1998. Utilizaram-se sementes básicas de cebola, obtidas junto à EMBRAPA-CPACT, das cultivares Aurora e Petrolini, colhidas em 1997. Inicialmente, verificou-se o grau de umidade de cada cultivar pelo método da estufa $105 \pm 3^{\circ} \mathrm{C}$ (Brasil, 1992). Em seguida, as sementes de cada cultivar foram divididas em duas porções iguais, uma das quais foi novamente enlatada e armazenada sob condições controladas $\left(10^{\circ} \mathrm{C} 40 \%\right.$ de umidade relativa do ar), formando os lotes $\mathrm{A} 1$ (cultivar Aurora) e P1 (cultivar Petrolini); a outra porção de cada cultivar foi acondicionada em recipiente de vidro com tampa de rosca e deixada em condições de ambiente natural, formando os lotes A2 (cultivar Aurora) e P2 (cultivar Petrolini). Os lotes foram armazenados por um ano, então, estabelecerem-se os tratamentos de osmocondicionamento.

Para o condicionamento osmótico das sementes utilizaram-se polietileno glicol (PEG 6.000) na concentração de $284,021 \mathrm{~g} / \mathrm{kg}$ de $\mathrm{H}_{2} \mathrm{O}$ e nitrato de potássio $\left(\mathrm{KNO}_{3}\right)$ na concentração de $20,2 \mathrm{~g} / \mathrm{kg}$ de $\mathrm{H}_{2} \mathrm{O}$. Adotaram-se três diferentes períodos de embebição das sementes: zero (controle), 24, e 48 horas. O controle constituiuse nas sementes secas que não sofreram osmocondicionamento. As sementes foram imersas em $250 \mathrm{ml}$ destas soluções, com aeração contínua, no interior de um germinador com temperatura de $20^{\circ} \mathrm{C}$. Depois de condicionadas, as sementes foram lavadas por três vezes em água destilada, submetidas à secagem superficial e deixadas em ambiente natural por uma hora. Após, foram colocadas em estufas com circulação de ar a $30^{\circ} \mathrm{C}$, até atingir os níveis iniciais de umidade. Uma vez secas, as sementes foram novamente divididas em duas porções iguais; uma foi imediatamente submetida às avaliações da qualidade fisiológica e a outra armazenada em sacos de papel Kraft, dentro de dessecador, por seis meses.

A qualidade fisiológica das sementes foi avaliada através de testes de germinação $\left(20^{\circ} \mathrm{C}\right.$ por 12 dias, Brasil, 1992), de germinação em temperatura sub-ótima, $\left(10^{\circ} \mathrm{C}\right.$ por 12 dias $)$, de velocidade de germinação, utilizando a fórmula de Edmond \& Drapala (1958) citada em Vieira \& Carvalho (1994) e de tempo requerido para a máxima germinação das sementes (Bodsworth \& Bewley, 1981), considerando-se raízes primárias com $5 \mathrm{~mm}$ de comprimento. Em função dos resultados observados na primeira etapa do experimento, após o armazenamento, somente foram avaliadas as sementes submetidas ao condicionamento por 24 horas de embebição. Adotou-se 0 delineamento experimental inteiramente ao acaso, com quatro repetições, com os tratamentos em esquema fatorial 2(lotes) x2 (substâncias) x3 (períodos de embebição), nas avaliações imediatas da qualidade fisiológica, e o fatorial 2(lotes) x2 (substâncias) x2 (períodos de embebição) nas avaliações após o armazenamento, para cada cultivar. As médias foram comparadas entre si pelo teste de Duncan a $5 \%$ de probabilidade e os dados em percentagem foram transformados para arc sen $(\mathrm{x} / 100)^{0,5}$, porém, nas TABELAS, são apresentadas as médias originais.

\section{RESULTADOS E DISCUSSÃO}

A análise de variância revelou diferenças significativas entre as médias de lotes, para todos os testes de avaliação da qualidade fisiológica das sementes. Os lotes A1, da cultivar Aurora e P1, da cultivar Petrolini, mostraram-se 
superiores aos respectivos lotes A2 e P2. O grau de umidade das sementes antes e após o armazenamento de doze meses, pode ser observado na TABELA 1. Nota-se que para os lotes mantidos sob condições controladas $\left(10^{\circ} \mathrm{C}\right.$ e $40 \%$ de umidade relativa do ar) não houve ganho de umidade. Para os lotes A2 e P2, mantidos sob condições de ambiente natural, houve incremento significativo no grau de umidade.

TABELA 1 - Grau de umidade de sementes de duas cultivares de cebola, Aurora e Petrolini, antese após armazenamento por um ano em condiçõescontroladas (lotes A1 e P1) e sob condições de ambiente natural lotes (A2 e P2).

\begin{tabular}{lcc}
\hline & \multicolumn{2}{c}{ Grau de umidade } \\
\hline Lotes & Umidade inicial & $\begin{array}{c}\text { Umidade após } \\
\text { armazenamento }\end{array}$ \\
\hline A1 & $7,8 \mathrm{a}$ & $7,9 \mathrm{a}$ \\
A2 & $7,8 \mathrm{a}$ & $9,8 \mathrm{~b}$ \\
P1 & $5,9 \mathrm{a}$ & $6,1 \mathrm{a}$ \\
P2 & $5,9 \mathrm{a}$ & $8,3 \mathrm{~b}$ \\
\hline C.V. (\%) & 2,11 & \\
\hline
\end{tabular}

Médias seguidas pelas mesmas letras na linha não diferem entre si pelo teste de Duncan a 5\%.

Conforme também observaram, em outras espécies Bradford (1986), Thanos et al. (1989) e Sampaio \& Giménez-Sampaio (1998), não houve redução na germinação das sementes de cebola osmocondicionadas após a secagem (TABELA 2). Isto pode ser atribuído a que a duração do condicionamento não permitiu que as sementes atingissem fases adiantadas do processo germinativo. Houve redução na percentagem de germinação das sementes armazenadas sob condições de ambiente natural (lotes A2 e P2) em relação às armazenadas sob condições controladas (A1 e P1). O osmocondicionamento com $0 \mathrm{KNO}_{3}$ proporcionou incrementos significativos na germinação em todos os tratamentos, em relação ao controle. No tratamento com o PEG, somente os lotes envelhecidos naturalmente, A2 e P2, mostraram germinação superior ao controle na embebição por 24 horas. Sampaio \& Giménez-Sampaio também verificaram que sementes de cenoura osmocondicionadas com soluções aeradas de $\mathrm{KNO}_{3}$ e PEG apresentaram taxas de germinação
TABELA 2 -Testes de germinação e de germinação em temperatura subótima de quatro lotes de sementes de cebola: A1 e A2, cv. Aurora; P1 e $\mathrm{P} 2$, cv. Petrolini, osmocondicionados com soluções aeradas de $\mathrm{KNO}_{3} \mathrm{e}$ PEG por diferentes períodos de embebição.

\begin{tabular}{|c|c|c|c|}
\hline \multicolumn{4}{|c|}{ Germinação (\%) } \\
\hline \multirow[b]{2}{*}{ Lotes } & \multirow{2}{*}{$\begin{array}{c}\text { Tempo de } \\
\text { embebição } \\
\text { (horas) }\end{array}$} & \multicolumn{2}{|c|}{$\begin{array}{c}\text { Substâncias } \\
\text { osmocondicionantes }\end{array}$} \\
\hline & & $\mathrm{KNO}_{3}$ & PEG \\
\hline & 0 (controle) & $76,5 b$ & $76,5 \mathrm{a}$ \\
\hline \multirow[t]{3}{*}{ A1 } & 24 & 85,1 aA & $80,0 \mathrm{aA}$ \\
\hline & 48 & 83,5 aA & $76,1 \mathrm{aB}$ \\
\hline & 0 (controle) & $65,0 \mathrm{~b}$ & $65,0 \mathrm{~b}$ \\
\hline \multirow[t]{2}{*}{$\mathrm{A} 2$} & 24 & 74,5 aA & $71,5 \mathrm{aA}$ \\
\hline & 48 & 71,1 aA & $68,0 \mathrm{abA}$ \\
\hline \multirow[t]{2}{*}{ C.V. (\%) } & & 5,54 & \\
\hline & 0 (controle) & $83,0 \mathrm{~b}$ & $83,0 \mathrm{a}$ \\
\hline \multirow[t]{3}{*}{ P1 } & 24 & 89,5 aA & $87,7 \mathrm{aA}$ \\
\hline & 48 & $86,6 a b A$ & $84,1 \mathrm{aA}$ \\
\hline & 0 (controle) & $73,5 \mathrm{c}$ & $73,5 b$ \\
\hline \multirow[t]{2}{*}{$\mathrm{P} 2$} & 24 & 86,7 aA & $78,6 \mathrm{aB}$ \\
\hline & 48 & $79,8 \mathrm{bA}$ & $73,0 \mathrm{bB}$ \\
\hline C.V. (\%) & & 5,07 & \\
\hline \multicolumn{4}{|c|}{ Germi nação em temperatura sub-ótima (\%) } \\
\hline \multirow{3}{*}{$\underline{\text { Lotes }}$} & $\begin{array}{l}\text { Tempo de } \\
\text { embebição }\end{array}$ & $\begin{array}{r}\text { Subs } \\
\text { osmocon }\end{array}$ & $\begin{array}{l}\text { âncias } \\
\text { icionantes }\end{array}$ \\
\hline & (horas) & $\mathrm{KNO}_{3}$ & PEG \\
\hline & 0 (controle) & $71,0 \mathrm{~b}$ & $71,0 \mathrm{~b}$ \\
\hline \multirow[t]{3}{*}{ A1 } & 24 & $85,1 \mathrm{aA}$ & $77,0 \mathrm{aB}$ \\
\hline & 48 & 84,5 aA & $72,0 \mathrm{bB}$ \\
\hline & 0 (controle) & $60,0 \mathrm{c}$ & $60,0 \mathrm{~b}$ \\
\hline \multirow[t]{2}{*}{$\mathrm{A} 2$} & 24 & 75,4 aA & $65,0 \mathrm{aB}$ \\
\hline & 48 & $69,0 \mathrm{bA}$ & $62,5 \mathrm{abB}$ \\
\hline \multirow[t]{2}{*}{ C.V. (\%) } & & 4,27 & \\
\hline & 0 (controle) & $77,5 \mathrm{c}$ & $77,5 \mathrm{ab}$ \\
\hline \multirow[t]{3}{*}{ P1 } & 24 & 88,1 aA & $81,0 \mathrm{aB}$ \\
\hline & 48 & $82,7 \mathrm{bA}$ & $76,5 \mathrm{bB}$ \\
\hline & 0 (controle) & $71,0 \mathrm{~b}$ & $71,0 \mathrm{~b}$ \\
\hline \multirow[t]{2}{*}{$\mathrm{P} 2$} & 24 & $81,1 \mathrm{aA}$ & $71,5 \mathrm{aB}$ \\
\hline & 48 & 79,7 aA & $67,0 \mathrm{bB}$ \\
\hline C.V. (\%) & & 4,07 & \\
\hline
\end{tabular}

Médias seguidas pelas mesmas letras, minúsculas na coluna e maiúsculas na linha, não diferem entre si pelo teste de Duncan a $5 \%$. 
superiores à testemunha. Os resultados evidenciaram que as sementes envelhecidas naturalmente e osmocondicionadas recuperaram a capacidade germinativa até valores próximos às não condicionadas e armazenadas sob condições controladas. Em cebola, pimentão e milho, também foi observado que as sementes envelhecidas artificialmente recuperaram a germinação após o condicionamento osmótico (Brocklehurst \& Dearman, 1983; Dearman et al., 1986; Thanos et al., 1989 e García et al., 1995).

No teste de germinação em temperatura sub-ótima (TABELA 2), verifica-se que apesar das condições de estresse térmico, o osmocondicionamento foi capaz de promover um melhor desempenho das sementes, principalmente naquelas envelhecidas sob condições ambientais, conforme também observaram Heydecker et al. (1973) e Broklehurst \& Dearman (1983). A resposta das duas cultivares ao osmocondicionamento com $0 \mathrm{KNO}_{3}$ foi semelhante, sendo em todos os casos, estatisticamente superior ao controle. O tratamento com o PEG se mostrou inferior ao tratamento com $0 \mathrm{KNO}_{3}$; somente a embebição por 24 horas mostrou resultados superiores ao controle, à exceção do lote $\mathrm{P} 1$, onde não foram observadas diferenças entre os tratamentos. A diferença entre a germinação do controle e das sementes osmocondicionadas pode ser explicada por Heydecker et al. (1973) e Taylor et al. (1998), que afirmam que as sementes osmocondicionadas apresentam maior taxa de germinação e vigor, em relação às não tratadas, quando expostas à condições de temperaturas desfavoráveis. Sampaio \& Giménez-Sampaio (1998), salientam que, mesmo tendo sido osmocondicionadas, a velocidade de germinação das sementes é diretamente afetada pela exposição das mesmas à temperaturas adversas, o que reforça o efeito positivo dos tratamentos de condicionamento osmótico.

A velocidade de germinação (TABELA 3) aumentou nas sementes submetidas ao priming, independentemente das substâncias utilizadas, entretanto a resposta ao $\mathrm{KNO}_{3}$ foi superior à do PEG. No lote A2, condicionado com $\mathrm{KNO}_{3}$ por 24 horas, a redução no tempo de germinação foi de 36 horas em relação à testemunha. Sampaio (1992), também observou que o desempenho de sementes de pimentão osmocondicionadas com $\mathrm{KNO}_{3}$ foi superior em relação às tratadas com PEG. O osmocondicionamento aumentou a velocidade de germinação de forma mais significativa nos lotes A2 e P2, ou seja, de menor qualidade fisiológica, fazendo com que estes
TABELA 3 -Velocidade de germinação de quatro lotes de sementes de cebola: A1 e A2,cv. Aurora; P1 e P2, cv. Petrolini, osmocondicionados com soluções aeradas de $\mathrm{KNO}_{3}$ e PEG por diferentes períodos de embebição.

\begin{tabular}{|c|c|c|c|}
\hline \multicolumn{4}{|c|}{ Velocidade de Germinação (dias) } \\
\hline \multirow[b]{2}{*}{ Lotes } & \multirow{2}{*}{$\begin{array}{l}\text { Tempo de } \\
\text { embebição } \\
\text { (horas) }\end{array}$} & \multicolumn{2}{|c|}{$\begin{array}{c}\text { Substâncias } \\
\text { osmocondicionantes }\end{array}$} \\
\hline & & $\mathrm{KNO}_{3}$ & PEG \\
\hline & 0 (controle) & $4,0 \mathrm{~b}$ & $4,0 \mathrm{c}$ \\
\hline \multirow[t]{3}{*}{$\mathrm{A} 1$} & 24 & 2,7 aA & $3,0 \mathrm{aB}$ \\
\hline & 48 & 2,9 aA & $3,3 \mathrm{bB}$ \\
\hline & 0 (controle) & $4,3 \mathrm{c}$ & $4,3 \mathrm{c}$ \\
\hline \multirow[t]{2}{*}{ A2 } & 24 & $2,8 \mathrm{aA}$ & $3,2 \mathrm{aB}$ \\
\hline & 48 & $3,0 \mathrm{bA}$ & $3,5 \mathrm{bB}$ \\
\hline \multirow[t]{2}{*}{ C.V. (\%) } & 1,52 & & \\
\hline & 0 (controle) & $3,5 b$ & $3,5 \mathrm{~b}$ \\
\hline \multirow[t]{3}{*}{ P1 } & 24 & $2,6 \mathrm{aA}$ & $3,0 \mathrm{aB}$ \\
\hline & 48 & 2,7 aA & $3,1 \mathrm{aB}$ \\
\hline & 0 (controle) & $4,1 \mathrm{~b}$ & $4,3 \mathrm{c}$ \\
\hline \multirow[t]{2}{*}{$\mathrm{P} 2$} & 24 & $2,7 \mathrm{aA}$ & $3,1 \mathrm{aB}$ \\
\hline & 48 & $2,8 \mathrm{aA}$ & $3,6 \mathrm{bB}$ \\
\hline C.V. (\%) & & 7,45 & \\
\hline
\end{tabular}

Médias seguidas pelas mesmas letras, minúsculas na coluna e maiúsculas na linha, não diferem entre si pelo teste de Duncan a $5 \%$.

atingissem valores similares aos alcançados pelos lotes A1 e P1 condicionados, o que confirma as afirmações de Brocklehurst \& Dearman (1983) de que a velocidade de germinação pode ser melhorada através do osmocondicionamento das sementes e que os efeitos mais positivos desse tratamento são observados naquelas sementes de vigor mais baixo. Bradford (1986) sugere que o priming promove um acúmulo de solutos no decorrer do processo, resultando em um maior potencial de turgor celular durante a reidratação das sementes, o que resultaria na emergência da radícula em menor tempo. Isto é particularmente importante quando se consideram as condições predominantes de solos frios na época de semeadura no Rio Grande do Sul. A maior velocidade de germinação proporcionada pelo osmocondicionamento, em relação ao controle, não deve ser analisada como um fator positivo isolado. Deve, sim, ser entendida como uma menor exposição das sementes às diversas 
fontes de estresse que normalmente ocorrem no solo, como variações extremas de temperatura, disponibilidade hídrica, ataque de insetos e/ou microrganismos, entre outras. Por outro lado, e como conseqüência direta da mais rápida emergência, o cultivo é beneficiado por um grau de uniformidade de desenvolvimento que, em condições normais, não ocorre.
Em relação ao tempo necessário para a máxima germinação das sementes (TABELA 4), considerando-se raízes com $5 \mathrm{~mm}$ de comprimento, verifica-se um comportamento diferenciado entre as sementes dos lotes $A 1$ e A2. No lote $A 1$, a maior diferença entre as taxas de germinação do controle e das sementes condicionadas foi observada aos dois dias de

TABELA 4 - Tempo necessário para a máxima germinação (raízes com $5 \mathrm{~mm}$ ) de sementes de quatro lotes de sementes de cebola: A1 e A2, cv. Aurora; P1e P2, cv. Petrolini, osmocondicionados com soluções aeradas de $\mathrm{KNO}_{3}$ e PEG, por diferentes períodos de embebição.

\begin{tabular}{|c|c|c|c|c|c|}
\hline \multicolumn{6}{|c|}{24 HORAS DE EMBEBIÇÃO } \\
\hline \multirow[t]{2}{*}{ Lotes } & \multirow[t]{2}{*}{ Substâncias } & \multicolumn{4}{|c|}{ Germinação (\%) } \\
\hline & & 2 dias & 4 dias & 6 dias & 8 dias \\
\hline & $\mathrm{KNO}_{3}$ & $34,4 \mathrm{a}$ & $88,0 \mathrm{a}$ & $94,0 \mathrm{a}$ & $94,1 \mathrm{a}$ \\
\hline \multirow[t]{3}{*}{ A1 } & PEG & $15,5 b$ & $78,5 \mathrm{~b}$ & $87,0 \mathrm{~b}$ & $89,0 \mathrm{~b}$ \\
\hline & controle & $10,4 \mathrm{c}$ & $71,4 d$ & $85,9 \mathrm{c}$ & $88,0 \mathrm{~b}$ \\
\hline & $\mathrm{KNO}_{3}$ & $23,5 \mathrm{a}$ & $76,0 \mathrm{a}$ & 84,5 a & $88,5 \mathrm{a}$ \\
\hline \multirow[t]{2}{*}{ A2 } & PEG & $12,0 \mathrm{~b}$ & $56,0 \mathrm{~b}$ & $81,0 \mathrm{~b}$ & $86,0 \mathrm{~b}$ \\
\hline & controle & $0,0 \mathrm{c}$ & $26,5 \mathrm{c}$ & $80,0 \mathrm{~b}$ & $84,5 \mathrm{bc}$ \\
\hline \multirow[t]{2}{*}{ C.V. (\%) } & & 5,8 & 2,75 & 2,17 & 1,75 \\
\hline & $\mathrm{KNO}_{3}$ & $44,9 \mathrm{a}$ & $91,0 \mathrm{a}$ & $95,5 \mathrm{a}$ & $98,0 \mathrm{a}$ \\
\hline \multirow[t]{3}{*}{ P1 } & PEG & $20,0 \mathrm{~b}$ & $74,0 \mathrm{~b}$ & $88,5 \mathrm{~b}$ & $91,5 \mathrm{~b}$ \\
\hline & controle & $9,0 \mathrm{c}$ & $61,5 c$ & $78,5 \mathrm{c}$ & $90,5 \mathrm{~b}$ \\
\hline & $\mathrm{KNO}_{3}$ & $40,5 \mathrm{a}$ & 91,0 a & $95,1 \mathrm{a}$ & $97,1 \mathrm{a}$ \\
\hline \multirow[t]{2}{*}{ P2 } & PEG & $9,0 \mathrm{~b}$ & $64,0 \mathrm{~b}$ & $87,0 \mathrm{~b}$ & $92,0 \mathrm{~b}$ \\
\hline & controle & $3,0 \mathrm{c}$ & $54,0 \mathrm{c}$ & $77,0 \mathrm{c}$ & $87,0 \mathrm{c}$ \\
\hline \multirow[t]{3}{*}{ C.V. (\%) } & & 10,44 & 9,85 & 5,49 & 2,75 \\
\hline & & 8 HORA & EMBEBI & & \\
\hline & $\mathrm{KNO}_{3}$ & $32,9 \mathrm{a}$ & $83,5 \mathrm{a}$ & $90,1 \mathrm{a}$ & $90,5 \mathrm{a}$ \\
\hline \multirow[t]{3}{*}{ A1 } & PEG & $14,0 \mathrm{~b}$ & $78,1 \mathrm{~b}$ & $88,0 \mathrm{a}$ & $89,0 a b$ \\
\hline & controle & $10,4 \mathrm{c}$ & $71,4 \mathrm{C}$ & $85,9 \mathrm{~b}$ & $88,0 \mathrm{~b}$ \\
\hline & $\mathrm{KNO}_{3}$ & $16,5 \mathrm{a}$ & $69,0 \mathrm{a}$ & $84,5 \mathrm{a}$ & $87,5 \mathrm{a}$ \\
\hline \multirow[t]{2}{*}{ A2 } & PEG & $7,0 \mathrm{~b}$ & $53,0 \mathrm{~b}$ & $80,5 \mathrm{~b}$ & $84,0 \mathrm{~b}$ \\
\hline & controle & $0,0 \mathrm{c}$ & $26,5 \mathrm{c}$ & $80,0 \mathrm{a}$ & $84,5 \mathrm{~b}$ \\
\hline \multirow[t]{2}{*}{ C.V. (\%) } & & 5,8 & 2,75 & 2,17 & 1,75 \\
\hline & $\mathrm{KNO}_{3}$ & $36,5 \mathrm{a}$ & 88,6 a & $92,1 \mathrm{a}$ & $94,5 \mathrm{a}$ \\
\hline \multirow[t]{3}{*}{ P1 } & PEG & $11,0 \mathrm{~b}$ & $69,0 \mathrm{~b}$ & $89,0 \mathrm{a}$ & $91,0 \mathrm{~b}$ \\
\hline & controle & $9,0 \mathrm{~b}$ & $61,5 c$ & $78,5 \mathrm{~b}$ & $90,5 \mathrm{~b}$ \\
\hline & $\mathrm{KNO}_{3}$ & $33,5 \mathrm{a}$ & $88,5 \mathrm{a}$ & $92,5 \mathrm{a}$ & $93,5 \mathrm{a}$ \\
\hline \multirow[t]{2}{*}{ P2 } & PEG & $10,9 \mathrm{~b}$ & $64,0 \mathrm{~b}$ & $85,5 \mathrm{~b}$ & $91,0 \mathrm{~b}$ \\
\hline & controle & $3,0 \mathrm{c}$ & $54,0 \mathrm{c}$ & $77,0 \mathrm{c}$ & $87,0 \mathrm{c}$ \\
\hline C.V. (\%) & & 10,44 & 9,85 & 5,49 & 2,75 \\
\hline
\end{tabular}

Médias seguidas pelas mesmas letras, minúsculas na coluna e maiúsculas na linha, não diferem entre si pelo teste de Duncan a $5 \%$. 
germinação, considerando o condicionamento com $\mathrm{KNO}_{3}$, independentemente do período de embebição. No lote $A 2$, as maiores diferenças entre as taxas de germinação das sementes osmocondicionadas e o controle foram observadas aos quatro dias. A cv. Petrolini mostrou percentagens finais de germinação superiores, matematicamente, à cv. Aurora. Não foram observadas diferenças no comportamento dos lotes $\mathrm{P} 1$ e P2 com relação à distribuição da germinação no tempo, em ambos períodos de embebição. As maiores diferenças entre as taxas de germinação dos controles e das sementes submetidas ao priming foram verificadas aos dois dias de germinação, independentemente dos tratamentos utilizados. Nota-se que à medida em que aumentam os dias de germinação, as diferenças na percentagem de germinação entre as sementes osmocondicionadas e o controle reduzem-se, ao ponto em que praticamente igualam-se, nos tratamentos com o PEG, à exceção do lote P2. O condicionamento osmótico com $\mathrm{KNO}_{3}$ mostrou germinação superior ao controle em todos os períodos avaliados, para as duas cultivares estudadas. Estes resultados sugerem que os tratamentos de osmocondicionamento em sementes de cebola recuperam a viabilidade, aumentam a velocidade de germinação, reduzindo, assim, o tempo decorrido entre a semeadura e a emergência das plântulas. Resultados semelhantes foram observados em outras espécies por Heydecker \& Gibbins (1978), Bodsworth \& Bewley (1981), Bradford (1986), Khan (1992), Hofmann \& Steiner (1994) e Liu et al. (1996).

A diferença de desempenho observada entre sementes condicionadas e não condicionadas nos testes realizados, conforme salientam Bradford, (1986), Khan (1992), Sung \& Chang (1993) e McDonald (1998), se deve a que durante o priming são iniciados vários processos como a mobilização das reservas, ativação e síntese-de-novo de numerosas enzimas, síntese de DNA e RNA, produção de ATP, além de reparos de danos no sistema de membranas sofridos durante o armazenamento.

O grau de umidade das sementes, osmocondicionadas ou não, após seis meses de armazenamento em condições ambientais pode ser observado na TABELA 5. Houve ganho de umidade durante o armazenamento das sementes, em relação à umidade inicial, como pode ser verificado na TABELA 1.

Uma das questões ainda pouco estudadas em relação ao condicionamento
TABELA 5 -Grau de umidade de quatro lotes de sementes de cebola: A1 e A2, cv. Aurora; P1 e P2, cv. Petrolini, submetidos ao osmocondicionamento com soluções aeradas de $\mathrm{KNO}_{3}$ e PEG por 24 horas de embebição, após seis meses de armazenamento em condições ambientais.

\begin{tabular}{|c|c|c|}
\hline & \multicolumn{2}{|c|}{ Grau de Umidade (\%) } \\
\hline \multirow[b]{2}{*}{ Lotes } & \multicolumn{2}{|c|}{ Substâncias Osmocondicionantes } \\
\hline & $\mathrm{KNO}_{3}$ & PEG \\
\hline Controle & \multicolumn{2}{|c|}{11,5} \\
\hline A1 & 11,9 & 11,8 \\
\hline Controle & \multicolumn{2}{|c|}{12,2} \\
\hline $\mathrm{A} 2$ & 11,6 & 11,4 \\
\hline Controle & \multicolumn{2}{|c|}{10,1} \\
\hline P1 & 11,5 & 11,1 \\
\hline Controle & \multicolumn{2}{|c|}{11,2} \\
\hline P2 & 11,7 & 11,3 \\
\hline
\end{tabular}

osmótico das sementes refere-se ao comportamento das mesmas na conservação de sua qualidade durante o armazenamento. O conhecimento desta importante variável, conforme salientam Sampaio \& GiménezSampaio (1998), pode determinar a viabilidade prática da técnica em função do tempo disponível para o preparo das sementes até a próxima época de semeadura. Os efeitos latentes do osmocondicionamento sobre a germinação, germinação em temperatura sub-ótima, velocidade de germinação e tempo necessário para a máxima germinação encontram-se, respectivamente, nas TABELAS 6,7 e 8 . O osmocondicionamento, tanto com o PEG como com $0 \mathrm{KNO}_{3}$, foi eficiente em manter a viabilidade das sementes mesmo após seis meses de armazenamento, para as duas cultivares (TABELA 6), entretanto, a resposta ao $\mathrm{KNO}_{3}$ foi superior. As testemunhas de ambas as cultivares sofreram redução significativa na germinação, principalmente, quando submetidas à estresse térmico (TABELA 6). O armazenamento também afetou a velocidade de germinação das sementes não osmocondicionadas (TABELA 7), induzindo a uma drástica redução. A sementes osmocondicionadas das duas cultivares também sofreram redução na velocidade de germinação, embora esta tenha ocorrido em menor escala. Alvarado \& Bradford (1988) e Liu et al. (1996) em 
tomate; Thanos et al. (1989) em pimentão e Hofmann \& Steiner (1994) em trigo, também observaram que sementes osmocondicionadas mantiveram sua viabilidade após o armazenamento.

Em relação ao tempo necessário para a máxima germinação (TABELA 8), as sementes osmocondicionadas, tanto da cultivar Aurora,

TABELA 6 -Testes de germinação e de germinação em temperatura sub-ótima de quatro lotes de sementes de cebola: A1 e A2, cv. Aurora; P1 e P2, cv. Petrolini, osmocondicionados por 24 horas de embebição com soluções aeradas de $\mathrm{KNO}_{3}$ e PEG e armazenados por seis meses.

\begin{tabular}{ccc}
\hline & \multicolumn{2}{c}{ Germinação (\%) } \\
\hline & \multicolumn{3}{c}{ Substâncias osmocondicionantes } \\
\cline { 2 - 3 } Lotes & $\mathrm{KNO}_{3}$ & $\mathrm{PEG}$ \\
\hline Controle & $64,0 \mathrm{~b}$ & $64,0 \mathrm{~b}$ \\
$\mathrm{~A} 1$ & $86,5 \mathrm{aA}$ & $82,1 \mathrm{aB}$ \\
Controle & $60,5 \mathrm{~b}$ & $60,5 \mathrm{~b}$ \\
$\mathrm{~A} 2$ & $80,6 \mathrm{aA}$ & $77,5 \mathrm{aB}$ \\
\hline C.V. (\%) & 2,97 \\
\hline Controle & $70,3 \mathrm{~b}$ & $70,3 \mathrm{~b}$ \\
P1 & $91,0 \mathrm{aA}$ & $87,5 \mathrm{aA}$ \\
Controle & $65,2 \mathrm{~b}$ & $65,2 \mathrm{~b}$ \\
P2 & $91,1 \mathrm{aA}$ & $86,0 \mathrm{aB}$ \\
\hline C.V. (\%) & 3,94 \\
\hline Germinação em temperatura sub-ótima (\%) \\
\hline \multicolumn{3}{c}{ Substâncias osmocondicionantes } \\
\cline { 2 - 3 } Lotes & $\mathrm{KNO}$ & $\mathrm{PEG}$ \\
\hline Controle & $47,5 \mathrm{~b}$ & $47,5 \mathrm{~b}$ \\
A1 & $84,5 \mathrm{aA}$ & $79,6 \mathrm{aB}$ \\
Controle & $33,5 \mathrm{~b}$ & $33,5 \mathrm{~b}$ \\
A2 & $78,0 \mathrm{aA}$ & $70,5 \mathrm{aB}$ \\
\hline C.V. (\%) & 2,56 & \\
\hline Controle & $48,9 \mathrm{~b}$ & $48,9 \mathrm{~b}$ \\
P1 & $89,1 \mathrm{aA}$ & $84,5 \mathrm{aB}$ \\
Controle & $44,5 \mathrm{~b}$ & $44,5 \mathrm{~b}$ \\
P2 & $87,0 \mathrm{aA}$ & $83,8 \mathrm{aA}$ \\
\hline C.V. (\%) & 3,91 \\
\hline
\end{tabular}

Médias seguidas pelas mesmas letras, minúsculas na coluna e maiúsculas na linha, não diferem entre si pelo teste de Duncan a $5 \%$. como da Petrolini, mantiveram o mesmo comportamento verificado imediatamente após os tratamentos de embebição controlada, enquanto os controles sofreram drástica redução, indicando que estas sementes sofreram deterioração durante o armazenamento, necessitando, portanto, de maior tempo para a reparação de danos no sistema de membranas.

O condicionamento osmótico de sementes de cebola, seguido de secagem, não só retardou o processo de deterioração como também permitiu um armazenamento satisfatório das sementes, sem que ocorressem perdas significativas na viabilidade das mesmas. Resultados semelhantes foram observados em cebola por Dearman et al. (1986) e em tomate por Alvarado \& Bradford (1988). Hofmann \& Steiner (1994) afirmam que o efeito do priming sobre a longevidade das sementes está na dependência da qualidade inicial das mesmas e do tempo de condicionamento. Assim, é possível afirmar que o condicionamento osmótico em soluções aeradas de $\mathrm{KNO}_{3}$ e PEG, seguido da desidratação das sementes foi efetivo em manter

TABELA 7 -Velocidade de germinação de quatro lotes de sementes de cebola: A1 e A2, cv. Aurora; P1 e P2, cv. Petrolini, osmocondicionados por 24 horas de embebição com soluções aeradas de $\mathrm{KNO}_{3}$ e PEG e armazenados por seis meses.

\begin{tabular}{lcc}
\hline \multicolumn{4}{c}{ Velocidade de germinação (dias) } \\
\hline \multicolumn{4}{c}{$\begin{array}{c}\text { Substâncias osmocondicionantes } \\
\text { Lotes }\end{array}$} & $\mathrm{KNO}_{3}$ & PEG \\
\hline Controle & $4,4 \mathrm{~b}$ & $4,4 \mathrm{~b}$ \\
$\mathrm{~A} 1$ & $3,0 \mathrm{aA}$ & $3,3 \mathrm{aB}$ \\
Controle & $4,9 \mathrm{~b}$ & $4,9 \mathrm{~b}$ \\
\multicolumn{1}{c}{ A2 } & $3,2 \mathrm{aA}$ & $3,7 \mathrm{aB}$ \\
\hline C.V. (\%) & \multicolumn{3}{c}{3,72} \\
\hline Controle & $4,3 \mathrm{~b}$ & $4,3 \mathrm{~b}$ \\
P1 & $2,9 \mathrm{aA}$ & $3,4 \mathrm{aB}$ \\
Controle & $5,0 \mathrm{~b}$ & $5,0 \mathrm{~b}$ \\
P2 & $3,1 \mathrm{aA}$ & $3,5 \mathrm{aB}$ \\
\hline C.V. (\%) & \multicolumn{3}{c}{8,25} \\
\hline
\end{tabular}

Médias seguidas pelas mesmas letras, minúsculas na coluna e maiúsculas na linha, não diferem entre si pelo teste de Duncan a $5 \%$. 
TABELA 8 -Tempo necessário para a máxima germinação (raízes com $5 \mathrm{~mm}$ ) de sementes de quatro lotes de sementes de cebola: A1 e A2, cv. Aurora; P1 e P2, cv. Petrolini, osmocondicionados por 24 horas de embebição com soluções aeradas de $\mathrm{KNO}_{3}$ e PEG e armazenados por seis meses.

\begin{tabular}{|c|c|c|c|c|c|}
\hline \multicolumn{6}{|c|}{ Germinação (\%) } \\
\hline Lotes & Substâncias & 2 dias & 4 dias & 6 dias & 8 dias \\
\hline & $\mathrm{KNO}_{3}$ & $41,5 \mathrm{a}$ & $89,0 \mathrm{a}$ & $92,0 \mathrm{a}$ & $92,0 \mathrm{a}$ \\
\hline \multirow[t]{3}{*}{ A1 } & PEG & $12,0 \mathrm{~b}$ & $78,0 \mathrm{~b}$ & $86,0 \mathrm{~b}$ & $86,0 \mathrm{~b}$ \\
\hline & controle & $6,9 \mathrm{c}$ & $67,0 \mathrm{c}$ & $78,0 \mathrm{c}$ & $84,5 \mathrm{c}$ \\
\hline & $\mathrm{KNO}_{3}$ & $17,0 \mathrm{a}$ & $82,5 \mathrm{a}$ & $85,5 \mathrm{a}$ & $86,5 \mathrm{a}$ \\
\hline \multirow[t]{2}{*}{ A2 } & PEG & $10,0 \mathrm{~b}$ & $67,0 \mathrm{~b}$ & $80,5 \mathrm{~b}$ & $83,0 \mathrm{~b}$ \\
\hline & controle & $0,0 \mathrm{c}$ & $30,0 \mathrm{c}$ & $75,0 \mathrm{c}$ & $81,5 \mathrm{c}$ \\
\hline \multirow[t]{2}{*}{ C.V. (\%) } & & 4,73 & 1,52 & 1,33 & 1,18 \\
\hline & $\mathrm{KNO}_{3}$ & $48,0 \mathrm{a}$ & $94,0 \mathrm{a}$ & $96,0 \mathrm{a}$ & $96,0 \mathrm{a}$ \\
\hline \multirow[t]{3}{*}{$\mathrm{P} 1$} & PEG & $25,0 \mathrm{~b}$ & $81,0 \mathrm{~b}$ & $88,5 \mathrm{~b}$ & $89,5 \mathrm{~b}$ \\
\hline & controle & $0,0 \mathrm{c}$ & $68,0 \mathrm{c}$ & $85,0 \mathrm{c}$ & $89,0 \mathrm{c}$ \\
\hline & $\mathrm{KNO}_{3}$ & $36,0 \mathrm{a}$ & $89,5 \mathrm{a}$ & $91,5 \mathrm{a}$ & $93,5 \mathrm{a}$ \\
\hline \multirow[t]{2}{*}{ P2 } & PEG & $12,0 \mathrm{~b}$ & $61,0 \mathrm{~b}$ & $77,5 \mathrm{~b}$ & $84,5 \mathrm{~b}$ \\
\hline & controle & $0,0 \mathrm{c}$ & $54,0 \mathrm{c}$ & $71,0 \mathrm{c}$ & $80,0 \mathrm{c}$ \\
\hline C.V. (\%) & & 4,95 & 1,63 & 1,57 & 1,55 \\
\hline
\end{tabular}

Médias seguidas pelas mesmas letras, minúsculas na coluna e maiúsculas na linha, não diferem entre si pelo teste de Duncan a $5 \%$.

a qualidade fisiológica das mesmas, mesmo após um período de seis meses de armazenamento. Este melhor desempenho pode estar relacionado com a eficiência do priming em reparar a integridade das membranas durante o processo de embebição, diminuindo as injúrias ao embrião provocadas pela rápida absorção de água.

$\mathrm{O} \mathrm{KNO}_{3}$, além de ter se mostrado como um bom agente osmocondicionante, poderia ter uma função adicional como fonte de potássio e nitrogênio para a semente em processo de germinação, como foi demonstrado por McGrady \& Cotter (1987) em sementes de pimentão. O condicionamento com o PEG não se mostrou tão efetivo em melhorar o desempenho das sementes de cebola, contrariando os resultados obtidos por outros autores em diversas culturas (Bodsworth \& Bewley, 1981; Brocklehurst \& Dearman, 1983; Dearman et al., 1986 e McDonald, 1998). Isto pode ser explicado pelo fato de que o PEG apresenta alta viscosidade em soluções aquosas, que somada à baixa taxa de difusão de $\mathrm{O}_{2}$, pode comprometer a disponibilidade de oxigênio para as sementes durante o condicionamento, podendo, inclusive, induzir a uma dormência secundária. Por outro lado, a condição de anoxia também pode ser acentuada em função de que as sementes de cebola, de acordo com Bujalski \& Nienow (1991), apresentam tegumento relativamente espesso, em média $0,3 \mathrm{~mm}$, o que poderia levar à fermentação e a produção de níveis tóxicos de etanol, prejudicando o metabolismo.

\section{CONCLUSÕES}

- A velocidade e a percentagem de germinação sob condições de estresse aumentam nas sementes de cebola osmocondicionadas.

- Sementes de cebola osmocondicionadas com soluções aeradas de $\mathrm{KNO}_{3}$ apresentam melhor desempenho em relação às condicionadas com PEG.

- O condicionamento osmótico pode reverter o processo de envelhecimento natural de sementes de cebola.

- Sementes de cebola osmocondicionadas mantém sua viabilidade por até seis meses de armazenamento. 


\section{REFERÊNCIAS BIBLIOGRÁFICAS}

ALVARADO, A.D.; BRADFORD, K.J. Priming and storage of tomato (Lycopersicon lycopersicum) seeds: I. Effects on storage temperature on germination rate and viability. Seed Science and Technology, v.16, p.601-612, 1988.

AMARAL, A.S.; GARCIA, A.; CASTRO, C.; STUMPF, C.L.; MORAES, E.C.; MADAIL, J.C.M.; DYNIA, J.F.; BICCA, L.H.F.; CARVALHO, R.P.L. Cultura da cebola para sementes no Rio Grande do Sul. Pelotas: EMBRAPA, CNPFT, 1987. 71p. (Circular Técnica, 12).

BODSWORTH, S.; BEWLEY, J.D. Osmotic priming of seeds of crop species with polyethylene glycol as a means of enhancing early and synchronous germination at cool temperatures. Canadian Journal of Botany, v.59, n.5, p.672-676, 1981.

BRADFORD, K.J. Manipulation of seed water relations via osmotic priming to improve germination under stress conditions. HotScience, v.21, n.5, p.1105-1112, 1986.

BRASIL. Ministério da Agricultura e da Reforma Agrária. Regras para análise de sementes. Brasília: SNDA/DNDV/CLAV, 1992. 365p.

BROCKLEHURST, P.A.; DEARMAN, J. Interaction between seed priming treatments and nine seed lots of carrot, celery and onion: I. Laboratory germination. Annals of Applied Biology, v.102, p.577-584, 1983.

BURGASS, R.W.; POWELL, A.A. Evidence for repair processes in the invigoration of seeds by hydratation. Annals of Botany, v.53, p.735-757, 1984.

BUJALSKI, W.; NIENOW, A.W. Large scale osmotic priming of onion seeds: a comparison of different strategies for oxygenation. Scientiae Horticulturae, v.46, p.13-24, 1991.

DEARMAN, J.; BROCKLEHURST, P.A.; DREW, R.L.K. Effects of osmotic priming and ageing on onion seed germination. Annals of Applied Biology, v.108, p.639-648, 1986.

GARCÍA, F.C.; JIMÉNEZ, L.F.; VÁZQUEZ-RAMOS, $\mathrm{J}$. Biochemical and citological studies on osmoprimed maize seeds. Seed Science Research, v.5, p.15-23, 1995.

HEYDECKER, W.; GIBBINS, B.M. The priming of seeds. Acta Horticulturae, v.83, p.213-223, 1978.

HEYDECKER, W.; HIGGINS, J.; GULLIVER, R.L. Accelerated germination by osmotic seed treatment. Nature, v.246, p.42-44, 1973.

HOFMANN, P.; STEINER, A.M. Seed quality as a cause for differences in longevity behavior after seed pretreatment in wheat (Tritucum aestivum L.). Seed Science Research, v.4, p.323-328, 1994.
KHAN, A.A. Preplant physiological seed conditioning. Horticultural Review, v.13, p.131-181, 1992.

KNYPL, J.S.; KHAN, A.A. Osmoconditioning of soybean seeds to improve performance at suboptimal temperaure. Agronomy Journal, v.73, p.112-116, 1981.

LIU, Y.; BINO, R.J.; VAN DER BURG, W.J.; GROOT, S.P.C.; HILHORST, W.M. Effects of osmotic priming on dormancy and storability of tomato (Lycopersicon esculentum Mill.) seeds. Seed Science Research, v.6, p.49-55, 1996.

McDONALD, M.B. Seed quality assessment. Seed Science Research, v.8, p.265-275, 1998.

McGRADY, J.J.; COTTER, D.J. Preplant seed treatments effects on growth and yield of chile pepper. HotScience, v.22, p.435-437, 1987.

MICHEL, B.E.; KAUFMAN, M.R. The osmotic potential of polyethylene glicol 6000. Plant Physiology, v.5, n.6, p.914-916, 1973.

POWELL, A.A. Seed improvement by selection and invigoration. Scientia Agricola, v.55, p.126-133, 1998. Número especial

SAMPAIO, N.V.; SAMPAIO-GIMÉNEZ, T. Viabilidade, vigor e armazenamento de sementes de cenoura (Daucus carota L.) submetidas ao précondicionamento osmótico. Revista Científica Rural, v.3, n.1, p.38-45, 1998.

SAMPAIO, T.M.G. Pre-acondicionamiento osmotico y recubrimiento de semillas de pimiento (Capsicum annum L.). Madrid, 1992. 266p. Tesis (Doctoral) - Universidad Poltécnica de Madrid.

SAVINO, G.; HAIGH, P.M.; LEO, P.de. Effects of presoaking upon seed vigour and viability during storage. Seed Science and Technology, v.7, p.57-64, 1979

SUNG, F.J.M.; CHANG, Y.H. Biochemical activities associated with priming of sweet corn seeds to improve vigor. Seed Science and Technology, v.21, p.97-105, 1993.

TAYLOR, A.G.; ALLEN, P.S.; BENNETT, M.A.; BRADFORD, K.J.; BURRIS, J.S.; MISRA, M.K. Seed enhancements. Seed Science Research, v.8, p.245-256, 1998.

THANOS, C.A.; GEORGHIOU, K.; PASSAM, H.C. Osmoconditioning and age of pepper seeds during storage. Annals of Botany, v.63, p.65-69, 1989.

VIEIRA, R.D.; CARVALHO, M.C. Testes de vigor em sementes. Jaboticabal: FUNEP, 1994. $164 p$.

Recebido para publicação em 04.03.99

Aceito para publicação em 26.07 .99 